\title{
A prospective study of von Willebrand factor levels and bleeding in pregnant women with type 1 von Willebrand disease
}

\author{
S. L. SOOD, $*$ A. H. JAMES, † M. V. RAGNI, A. D. SHAPIRO, C. WITMER, $\|^{*}$ R. VEGA, ** \\ D. BOLGIANO $+\uparrow$ and B. A. KONKLE $\uparrow+\uparrow+$ \\ *Hematology/Oncology, University of Michigan, Ann Arbor, MI; †Department of OB/GYN, Duke University Medical Center, \\ Durham, NC; $\ddagger$ Department of Medicine, Division Hematology/Oncology, University of Pittsburgh and Hemophilia Center of

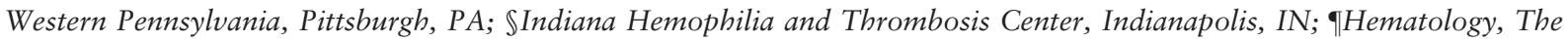 \\ Children's Hospital of Philadelphia, Philadelphia, PA; *University of Pennsylvania, Philadelphia, PA; †Bloodworks \\ Northwest, Seattle, WA; and $\$$ Department of Medicine, Division of Hematology, University of Washington, Seattle, WA, \\ USA
}

Women with von Willebrand disease (VWD) are at increased risk of pregnancy-related bleeding, including postpartum haemorrhage (PPH) compared to women without VWD [1-4]. In healthy women without VWD, levels of VWF and FVIII increase two- to fourfold during pregnancy, peaking within $24 \mathrm{~h}$ postpartum and decrease to baseline levels by 1 month postpartum [5-7]. Type 1 VWD, accounting for approximately $80 \%$ of patients with VWD, is characterized by a parallel deficiency of von Willebrand factor antigen and activity. In cross-sectional analyses of values in women with type 1 VWD, levels of VWF and FVIII also increase during pregnancy, usually to within the normal range $[8,9]$. Prospective analyses of levels in women with VWD in the peripartum period show that levels peak early after delivery and return to baseline by approximately 3 weeks postpartum $[10,11]$. Longitudinal data evaluating changes earlier in pregnancy are lacking.

The goal of this study was to model changes in VWF levels during and up to 6 weeks postpartum in women with type 1 VWD and correlate findings with blood loss. A secondary goal was to identify potential predictors of bleeding with delivery in women with type 1 VWD.

Women with type $1 \mathrm{VWD}$, defined as at least one value of VWF antigen (VWF:Ag) or VWF activity (VWF:Act) $<50 \%$, VWF Act/Ag $>0.7$, and compatible history of mucosal bleeding prepregnancy, age 18 or older, were recruited prior to 36 weeks gestation. The study was terminated early due to low enrolment. Women with a twin gestation, additional bleeding disorder, or use of anticoagulant or antiplatelet therapy

Correspondence: Barbara A. Konkle, MD, Director, Clinical and Translational Research, Bloodworks Northwest, 921 Terry Avenue, Seattle, WA 98104, USA.

Tel.: 206689 6191; fax: 206-689-8341;

e-mail: BarbaraK@BloodworksNW.org

Accepted after revision 25 July 2016

DOI: 10.1111/hae.13086 were excluded. All subjects gave written informed consent before enrolment, and the study was IRB approved at each participating institution.

Baseline data included demographics, bleeding symptoms, a modified bleeding score[12] and prior history of PPH, if any. Data collected at time of labour, 24-48 h, 48 h-1 week, 1-2 and 6 weeks postpartum included method of delivery, complications, estimated blood loss (EBL), need for haemostatics or blood products and bleeding or VWD diagnosis in the infant. FVIII, VWF:Ag and VWF:Act were obtained monthly after enrolment, at presentation in labour and postpartum $(12,24$ and $48 \mathrm{~h}$ and 1,2 and 6 weeks). Cord blood was obtained at the time of delivery. Platelet-poor plasma was prepared locally from all samples $(3.2 \% \mathrm{Na}$ citrate anticoagulation) within $3 \mathrm{~h}$ of collection, frozen at $-80^{\circ} \mathrm{C}$ and assayed centrally [one-stage factor VIII activity (MDA 180, Platelin L activator, BioMerieux, Durham, NC), VWF:Ag and VWF:Act by ELISA (American Biochemical and Pharmaceuticals Ltd, Epsom, Surrey, UK)].

Univariate analyses were carried out with the student $t$-test and chi-squared test to compare the difference in continuous and categorical variables, respectively. Change in VWF:Ag levels during gestation and postpartum was modelled using longitudinal regression analysis. A mixed-effects exponential growth model was used in the gestational period and an exponential decay model was used in the postpartum period. All analyses were performed using either $\mathrm{R}$ version 2.12 ( $\mathrm{R}$ Foundation for Statistical computing, Vienna, Austria) or Stata 12 (StataCorp, College Station, TX).

Twelve women were recruited from four institutions, with a median age of 31.3 years (range: 19-43). All were Caucasian of non-Hispanic ethnicity. One patient dropped out at 21 weeks' gestation. Most were blood type $\mathrm{O}(67 \%)$, and 5 of $12(42 \%)$ were nulliparas. Three subjects reported prior PPH $(27 \%)$. The mean baseline bleeding score was 8 [standard deviation (SD) 7]. Mean weeks' gestation at delivery 
was 39 (SD: 1), with two caesarean deliveries (18\%). Seven women $(64 \%)$ used epidural anaesthesia, and one woman each used spinal, general, local or no anaesthesia. Seven women (64\%) suffered some degree of genital tear. Mean EBL was $528 \mathrm{~mL}$ (SD: 354). One woman experienced immediate $\mathrm{PPH}$, ascribed to uterine atony and requiring a 2-unit $\mathrm{RBC}$ transfusion, and one woman had secondary PPH at $48 \mathrm{~h}$ and selftreated at home with intranasal desmopressin. Three women were treated with VWF concentrate peri- and postpartum, one for a history of $\mathrm{PPH}$, one for low VWF levels and the third for unclear reasons. None of the women required readmission, ICU stay or invasive procedures to stop bleeding.

Mean VWF:Ag, VWF:Act and FVIII levels at baseline, at presentation in labour and 6 weeks postpartum are shown in Table 1. VWF:Ag and VWF:Act levels correlated well throughout for each woman $(r$ 0.91, $P<0.01)$. The rate of change of VWF levels was heterogeneous and varied individually, with differences between VWF:Ag value at baseline vs. labour ranging from 43 to $164 \%$ and labour vs. 6 weeks postpartum ranging from 21 to $128 \%$ (Fig. 1).

During the gestational period, a mixed-effects exponential growth model best fit the rise in VWF:Ag level at labour relative to prepregnancy, $\mathrm{VWF}: \mathrm{Ag}=\exp$ $(0.028 \times$ gestational age in weeks $), S D: 0.007$. In this model, VWF:Ag is predicted to double from 19 weeks upwards and some individuals would not double prior to entering labour $\left(R_{\mathrm{LR}}{ }^{2}=0.58\right)$. Postpartum, an exponential decay model was fit to the decline in VWF:Ag from labour to 2 weeks PP, VWF:Ag $=\exp$ $(-0.40 \times$ gestational age in weeks), SD: 0.19 $\left(R^{2}=0.79\right)$. This model predicted VWF:Ag levels should return to baseline by mean 3.8 weeks (SD: 2.6) postpartum. Poor fit of the exponential decay model in the 2- to 6-week postpartum time period suggests that after 2 weeks postpartum, decay in VWF:Ag is no longer exponential. Modelling results were similar if VWF:Act was used. In the study by James and colleagues, which elucidated the changes in VWF levels postpartum in more detail, VWF levels decayed rapidly and approached baseline at 1 week and then more slowly reached baseline levels at 3 weeks [11], consistent with our findings.

Using cross-sectional analyses, Cadroy and colleagues modelled changes in VWF:Ag levels during normal pregnancy over 5-39 weeks' gestation [9]. They also used an exponential growth model to fit their independent VWF:Ag measurements, which was expressed as VWF:Ag $=6.39 * \exp [0.017 \times$ Gest.Age (weeks)]. Cadroy's estimates of VWF:Ag changes in non-VWD women (0.017) were at the low end of growth rate estimates from our model of type 1 VWD women (0.016-0.039), suggesting that VWF:Ag levels change more dynamically during pregnancy in women with type 1 VWD than in normal women.

Increased EBL was associated with caesarean delivery $(r, P$-value: $0.76,0.02)$ and manual placenta delivery $(0.76,0.02)$. Increased haemoglobin loss from 36 weeks' gestation to $24 \mathrm{~h}$ postpartum correlated with episiotomy $(0.75,0.03)$ and degree of tear $(0.99$, 0.02 ). Most tears were minor [mean degree 2 (range 1-3)]. No significant correlation was found with VWF levels at labour or bleeding score. The woman who bled during delivery had the highest peak VWF levels in the study (VWF:Ag 215\% and VWF:Act 183\% at labour presentation) and uterine atony, the most common cause of primary PPH.

Haemostatic outcomes and VWF levels were recorded in the neonates born to the study subjects. All were within adult normal ranges and did not correlate significantly with maternal levels at labour or baseline (Table 1). Based on the presumed autosomal

Table 1. VWD laboratory parameters* over time.

\begin{tabular}{lrrr}
\hline & $n$ & $\%$ VWF:Ag (SD) & \% VWF:Act (SD) \\
\hline Baseline & 11 & $41.1(7.1)$ & $34.4(8.4)$ \\
Labour & 11 & $136.4(50.8)$ & $128.9(47.8)$ \\
6 weeks PP & 10 & $57.8(22.8)$ & $52.1(25.4)$ \\
Infant cord blood & 9 & $97.9(35.8)$ & $96.2(34.8)$ \\
\hline
\end{tabular}

"Values shown are mean [standard deviation (SD)].

Fig. 1. von Willebrand factor antigen (VWF Ag) levels prior to and following labour. Women with a VWF:Ag < $50 \%$ prior to pregnancy had VWF:Ag levels measure at time points prior to, at presentation in labour and postpartum (a). Values drawn during the first 2.5 weeks postpartum are shown in (b).
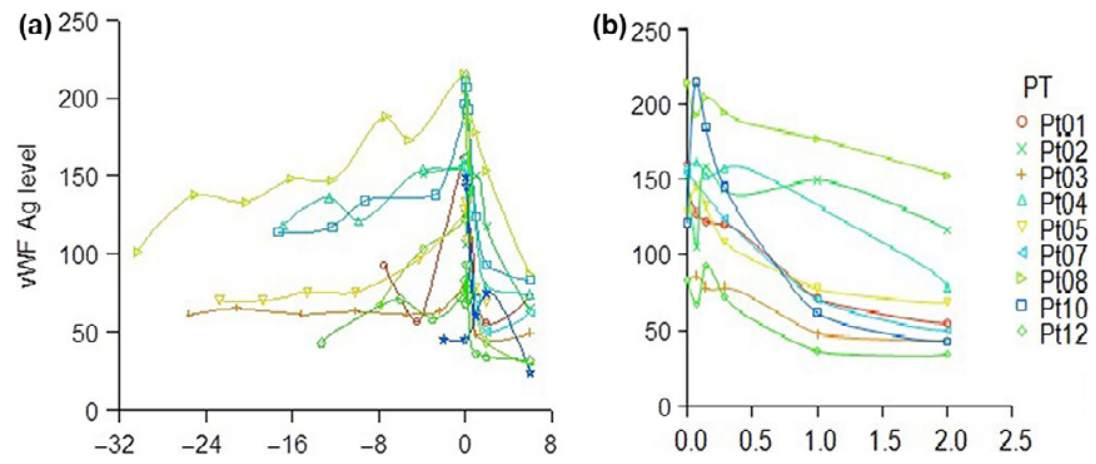
dominant inheritance pattern of type $1 \mathrm{VWD}$, there is a $50 \%$ chance of having an affected child. In general, it is assumed that neonates with type 1 VWD have elevated levels at birth secondary to the stress of birth and should not experience haemorrhage with haemostatic challenges. In our study, no infants had bleeding symptoms and were diagnosed with VWD or bled with procedures $(03$; one circumcision, two blood draws) in the first 6 weeks of life. We did not have IRB approval to follow the infants further.

We did not perform VWF mutation analysis in our patients. If performed in a larger number of women with VWD, such analyses might help explain the observed heterogeneity in responses. Type 1 VWD results from mutations that affect VWF synthesis, processing and/or secretion $[14,15]$. It would follow that some defects may suppress or prevent expression of pregnancy-related increases.

The major limitation of our study is the small number of patients enrolled. Compounding this is the fact that type 1 VWD is a heterogeneous disease with a wide variety of genotypes and phenotypes. Our definition of type 1 VWD was liberal with a baseline VWF: Ag or Act $<50 \%$, and inconsistent with NHLBI recommendations of values $<30 \%$ [13]. Nevertheless, we also required a history of excessive mucosal bleeding, substantiated by the women's elevated bleeding scores. Despite these limitations, the strengths of our study include its prospective nature and close follow-up, with chart-verified obstetric data and lack of dependence on patient recall.

In conclusion, women with type 1 VWD have highly individual and heterogeneous rates of rise and decline of VWF levels during gestation and postpartum. An exponential growth and decay model was fit to the VWF:Ag peripartum levels up to 2 weeks postpartum. In our study, VWF levels were not correlated significantly with blood loss, although, of note, all subjects' VWF levels were $>50 \%$ at the time of delivery. The children born to study subjects had normal FVIII and VWF levels and did not have bleeding complications. While this study is small and the population is homogenous, it confirms the variable rise and fall in VWF levels and supports the practice of assessing factor levels in women with VWD during pregnancy.

\section{Acknowledgements}

The study was funded, in part, by an investigator-initiated research grant to BAK from CSL Behring.

\section{Author contributions}

BAK conceived the original study question. SLS, AHJ, CW and BAK designed the study. MR, RV and AS were instrumental in recruiting subjects. SLS and DB performed primary data analysis, with modelling performed by DB. All authors had access to data. SLS and BAK wrote the manuscript, with substantial input and modification from the other authors.

\section{Disclosures}

Some of the authors have received funding from manufacturers of products used to treat VWD. BK received research support from CSL Behring, Octapharma, Baxalta, and consultancy fees from CSL Behring, Baxalta; $\mathrm{AHJ}$ is a member of advisory boards, CSL Behring, Baxalta; MVR received research support from Baxalta, CSL Behring, and consultancy fees from Baxalta.

\section{References}

1 Kirtava A, Drews C, Lally C, Dilley A, Evatt B. Medical, reproductive and psychosocial experiences of women diagnosed with von Willebrand's disease receiving care in haemophilia treatment centres: a case-control study. Haemophilia 2003; 9: 292-7.

2 James AH, Jamison MG. Bleeding events and other complications during pregnancy and childbirth in women with von Willebrand disease. J Thromb Haemost 2007; 5: 1165-9.

3 Chi C, Bapir M, Lee CA, Kadir RA. Puerperal loss (lochia) in women with or without inherited bleeding disorders. Am J Obstet Gynecol 2010; 203(56): e1-5.

4 Kouides PA, Phatak PD, Burkart P et al. Gynaecological and obstetrical morbidity in women with type I von Willebrand disease: results of a patient survey. Haemophilia 2000; 6: 643-8.

5 Sanchez-Luceros A, Meschengieser SS, Marchese C et al. Factor VIII and von Willebrand factor changes during normal pregnancy and puerperium. Blood Coagul Fibrinolysis 2003; 14: 647-51.
6 Sie P, Caron C, Azam J et al. Reassessment of von Willebrand factor (VWF), VWF propeptide, factor VIII: $\mathrm{C}$ and plasminogen activator inhibitors 1 and 2 during normal pregnancy. Br J Haematol 2003; 121: 897-903.

7 Drury-Stewart DN, Lannert KW, Chung DW et al. Complex changes in von Willebrand factor-associated parameters are acquired during uncomplicated pregnancy. PLOS ONE 2014; 9: e112935.

8 Huq FY, Kulkarni A, Agbim EC, Riddell A, Tuddenham E, Kadir RA. Changes in the levels of factor VIII and von Willebrand factor in the puerperium. Haemophilia 2012; 18: 241-5.

9 Cadroy Y, Grandjean H, Pichon J et al. Evaluation of six markers of haemostatic system in normal pregnancy and pregnancy complicated by hypertension or pre-eclampsia. $\mathrm{Br} \mathrm{J}$ Obstet Gynaecol 1993; 100: 416-20.

10 Kadir RA, Lee CA, Sabin CA, Pllard D, Economides DL. Pregnancy in women with von Willebrand's disease or factor XI deficiency. $\mathrm{Br}$ J Obstet Gynaecol 1998; 105: 314-21.

11 James AH, Konkle BA, Kouides P et al. Postpartum von Willebrand factor levels in women with and without von Willebrand disease and implications for prophylaxis. Haemophilia 2015; 21: 81-7.

12 Tosetto A, Castaman G, Rodeghiero F. Assessing bleeding in von Willebrand disease and bleeding score. Blood Rev 2007; 21: 89-97.

13 Nichols WL, Hultin MB, James AH et al. von Willebrand disease (VWD): evidence-based diagnosis and management guidelines, the National Heart, Lung, and Blood Institute (NHLBI) Expert Panel report (USA). Haemophilia 2008; 14: 171-232.

14 Goodeve A, Eikenboom J, Castaman G et al. Phenotype and genotype of a cohort of families historically diagnosed with type 1 von Willebrand disease in the European study. Molecular and clinical markers for the diagnosis and management of type 1 von Willebrand disease. Blood 2007; 109: 112-21.

15 James PD, Notley C, Hegadorn C et al. The mutational spectrum of type 1 von Willebrand disease. Results from a Canadian cohort study. Blood 2007; 109: 145-54. 